\title{
UTILIZAÇÃO DE SIG COMO SUBSÍDIO A IDENTIFICAÇÃO DE USOS CONFLITANTES EM ÁREAS DE PRESERVAÇÃO PERMANENTE: ESTUDO DE CASO NO MUNICÍPIO DE ITABUNA, BAHIA
}

\author{
Kaique Brito Silva ${ }^{(a)}$, Vanessa Paim dos $\operatorname{Santos}^{(\mathrm{b})}$, Ana Luzia Campos ${ }^{(\mathrm{c})}$, João Paulo Santos \\ Vita $^{(\mathrm{d})}$, Gabriel Ganem ${ }^{(\mathrm{e})}$ \\ (a) Programa de Pós-Graduação em Geografia, Universidade Estadual de Campinas, São Paulo. \\ kbritofb96@hotmail.com \\ (b) Pós graduação em Meio Ambiente, Universidade Estadual de Santa Cruz, Bahia. vampaim@ @otmail.com \\ (c) Faculdade de Tecnologia e Ciências - FTC, Bahia. anablonnd@gmail.com \\ (d) Faculdade de Tecnologia e Ciências - FTC, Bahia. joaopcivil@gmail.com \\ (e) Pós-Graduação em Modelagem Computacional, Universidade Estadual de Santa Cruz, Bahia. ganem@ gmail.com
}

Eixo: uso e ocupação das terras e legislação ambiental

\begin{abstract}
Resumo
Desmatamentos em Áreas de Preservação Permanentes ao longo dos corpos hídricos surgem como processos denominados de uso conflitante. Enquanto a legislação nacional, por meio do Código Florestal Brasileiro, determina que tais áreas devam permanecer vegetadas, as alternâncias do uso do solo fazem com que diversos municípios apresentem défict de cobertura vegetal ciliar. O município de Itabuna, no sul da Bahia, está inserido nesse âmbito, considerando a paisagem atual ao longo de seu principal rio, o Cachoeira. O objetivo desse trabalho é demonstrar como a utilização das técnicas derivadas de um SIG funciona como subsídio a leitura de ambientes que envolvem os Uso e ocupação das Terras conflitantes as normas legais, especificamente dimensionando a ausência de vegetação ao longo das matas ciliares, permitindo compreender o cenário das áreas legais em um trecho do rio Cachoeira, estado da Bahia.
\end{abstract}

Palavras chave: Uso do solo, preservação, hidrografia, Sul da Bahia

\section{Introdução}

O rio Cachoeira, na região sul da Bahia, é um rio de dimensões regionais que perpassa os municípios de Itapé, Itabuna e Ilhéus, chegando até o Oceano Atlântico. Inserido no domínio Mata Atlântica, forma paisagens ao longo das cidades congregando zonas antropizadas com a presença de áreas vegetadas em seu percurso de aproximadamente $50 \mathrm{~km}$. Em termos ambientais, o uso e ocupação das terras no sul da Bahia durante dos últimos dois séculos era majoritariamente pautado na produção de Cacau, numa forma de manejo denominada "Cabruca", que permite o consórcio entre a árvore de cacau com espécies arbóreas da Mata Atlântica. Dessa forma, pode-se afirmar que historicamente as margens do rio Cachoeira eram predominantemente tomadas por cobertura vegetal. 
Entretanto, devido as alternâncias das atividades econômicas após a crise do Cacau (década de 1980) agora pautadas em Agropecuária e Serviços, a presença da Mata Atlântica torna-se rarefeita ao longo das margens dos rios regionais, num processo de retirada extensiva de matas ciliares (SILVA et al. 2015). Dentro desse processo, o município de Itabuna, principal pólo econômico da região Sul da Bahia, também assiste ocupações ao longo das margens do rio Cachoeira, seja na forma de pastagens, atividades industriais ou aglomerados urbanos.

As matas ciliares são, segundo o atual Código Florestal Brasileiro (CFB), elencadas como Áreas de Preservação Permanente (APP's), no intuito de amenizar os processos de assoreamento em corpos d'água e manutenção do solo em terrenos fluviais (BRASIL, 2002). Os processos que desencadeiam a ausência de vegetação nativa em áreas definidas como APP's são denominados como "uso conflitante". Ainda segundo o atual $\mathrm{CFB}$, as respectivas classes de APP's relacionadas a cursos d'água devem obedecer às seguintes dimensões (Tabela I):

Tabela I - Dimensões de APP's para cursos dágua segundo o Código Florestal Brasileiro. Lei nº12.651/12:

I - as faixas marginais de qualquer curso d'água natural perene e intermitente, excluídos os efêmeros, desde a borda da calha do leito regular, em largura mínimade:

a) 30 (trinta) metros, para os cursos d'água de menos de 10 (dez) metros de largura;

b) 50 (cinquenta) metros, para os cursos d'água que tenham de 10 (dez) a 50 (cinquenta) metros de largura;

c) 100 (cem) metros, para os cursos d'água que tenham de 50 (cinquenta) a 200 (duzentos) metros de largura;

d) 200 (duzentos) metros, para os cursos d'água que tenham de 200 (duzentos) a 600 (seiscentos) metros de largura;

e) 500 (quinhentos) metros, para os cursos d'água que tenham largura superior a 600 (seiscentos) metros

Nessa perspectiva, o objetivo principal desse trabalho foi identificar, através de um Sistema de Informação Geográfica (SIG), as dimensões das atuais classes de uso da terra que substituíram as doravantes matas ciliares do Rio Cachoeira no município de Itabuna. Andrade e Romero (2005), Mascarenhas et a.l (2009) e Nowatzki et al. (2010), são exemplos de trabalhos que expõem a aplicação dos SIG's na identificação de cobertura vegetação e delimitação de APP's em corpos d'água, visando a comparação com a legislação vigente e descrevendo paisagens ciliares. 


\section{Materiais e Métodos}

A área definida para o estudo corresponde ao trecho do rio Cachoeira inserido no município de Itabuna, especificamente entre as coordenadas $14^{\circ} 27^{\prime} 27^{\prime \prime} \mathrm{S} / 39^{\circ} 15^{\prime} 09^{\prime \prime} \mathrm{O}$ e $14^{\circ} 54^{\prime} 00^{\prime \prime} \mathrm{S} / 39^{\circ} 22^{\prime} 07^{\prime \prime} \mathrm{S}$ (Figura 1). No recorte em estudo, o mesmo possui $20,7 \mathrm{~km}$ de extensão alcançando a sede urbana do município no quilômetro 10. Possui uma média de largura de 47,8 metros em toda a sua extensão (SANTOS, 2005). Em termos hidrográficos, o rio Cachoeira é originado de uma confluência entres os rios Salgado e Colônia, no município de Itapé, limítrofe oeste. Se estende até o Oceano Atlântico com exutório na Baía do Pontal, na cidade de Ilhéus.

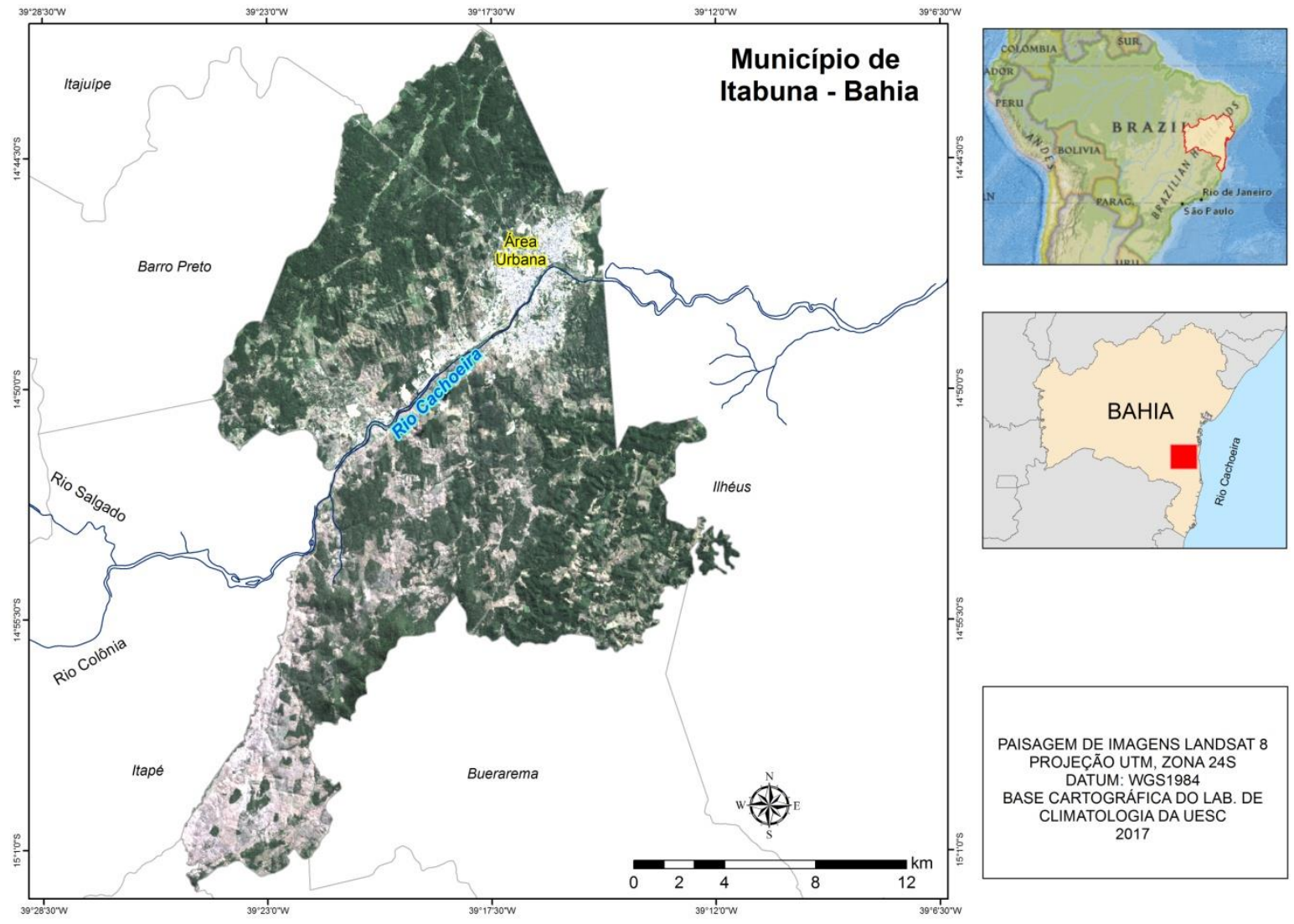

Figura 1 - Localização do Município de Itabuna - Bahia

Para delimitação das APP's e respectivos mapeamentos das classes de Uso da Terra inseridas no interior das mesmas, utilizou-se o Sistema de Informação Geográfica ArGis 10.3. O passo a passo metodológico consistiu-se em: (1) Obtenção da Imagem de satélite LandSat 8, datada de 01/2017, respectiva ao ponto orbital de número 237: a resolução das bandas espectrais deste sensor é de 30 metros por pixel - entretanto, através de melhoramentos de resolução com a banda "Pancromática" (comando creat pan-sharpened), atingiu-se uma resolução de 15 metros por pixel. A partir desse processamento da imagem, realizou-se uma 


\section{OS DESAFIOS DA GEOGRAFIA FÍSICA NA FRONTEIRA DO CONHECIMENTO \\ Instituto de Geociências - Unicamp \\ Campinas - SP \\ 28 de Junho à 02 de Julho de 2017}

classificação da imagem através da obtenção de pontos de controle, em campo, e criação de polígonos sobrepostas as classes de uso da terra aparentes, bem como o espelho d'água do percurso do rio. Cabe frisar que, devido a pouca dimensão da área em estudo, optou-se por não realizar nenhum tipo de classificação automatizada (como class. supervisionada ou NDVI, por exemplo); (2) Após o levantamento das classes de uso do terra, foram criados os Buffers que simulam as APP's respectivas aos valores de largura do rio Cachoeira: os inputs desse processo no SIG é através da ferramenta Buffer Analysis; (3) Após a determinação das classes de uso da terra e contornos de APP's, realizou a extração das mesmas apenas para os limites das áreas de preservação. Esse processo foi realizado na ferramenta Clip Analysis. Através da tabela de atributos das camadas (Layers) geradas, obteve-se a dimensão das classes que formam o uso conflitante, exportadas em hectares e porcentagem total.

\section{Resultados e Discussão}

As APP's do rio Cachoeira dentro do município de Itabuna enquandram-se nas classes de dimensões de 50 e $100 \mathrm{~m}$, com o curso d'água apresentando largura média de 50,3 m. Dentro dos limites designados pelo CFB como áreas de preservação, foram identificadas as seguintes classes de uso do solo: (1) Mata Atlântica: áreas com presença de vegetação desenvolvida, geralmente associadas a áreas de mata de propriedades rurais (2) Pastagens: áreas manejadas para criação de gados ou atribuídas a locais que requeiram ausência de vegetação desenvolvida (para fins de saneamento básico ou segurança pública, por exemplo), com aspecto mais ralo quando há atividades atuais ou capoeiras, quando abandonadas; (3) Zonas Urbanizadas: presenças de elementos lineares típicos de processo de urbanização, como loteamentos e arruamentos; (4) Atividades Industriais: Edificações, pátios e demais estruturas com finalidade de guarnecer as indústrias locais; (5) Áreas Degradadas: áreas com solo exposto associadas a atividades de erosão, extração de areia fluvial ou aplainamentos do terreno abandonados. A Tabela II traz as dimensões das classes mapeadas com respectivas dimensões:

Tabela II - Dimensões das classes de Uso da terra inseridas em APP's

\begin{tabular}{ccc}
\hline Classes de Uso do Solo & Hectares & Porcentagem \\
\hline Mata Atlântica & 11,7 & 3,2 \\
Pastagens & 132 & 35,3 \\
Zonas Urbanizadas & 180,1 & 48,1 \\
AtividadesIndustriais & 6,2 & 1,6 \\
Áreas Degradadas & 43,8 & 11,8 \\
\hline Total & 373,8 & 100
\end{tabular}




\section{OS DESAFIOS DA GEOGRAFIA FÍSICA NA FRONTEIRA DO CONHECIMENTO \\ Instituto de Geociências - Unicamp \\ Campinas - SP \\ 28 de Junho à 02 de Julho de 2017}

As Zonas Urbanizadas correspondem a matriz da paisagem do uso do solo das APP's: os processos de ocupação dessas áreas são resultados de uma evolução de ocupações ribeirinhas ligadas a sede municipal. As principais rodovias que perpassam a cidade, a saber BR 101 e BR 415, apresentam eixos adjacentes as margens do rio Cachoeira, o que favoreceu a instalação das indústrias que formam o Distrito Industrial, na zona leste da cidade. Essas vias também favorecem o processo de retirada de areia fluvial, comercializada na construção civil. Os "areais" formados pelas concavidades da extração, são predominantemente as áreas que compõe as Áreas Degradadas.

Em relação a vegetação nativa, os remanescentes de Mata Atlântica, que por lei deveriam ocupar em 100\% as áreas de APP, ocupam apenas 3,2\% do total de 373,8 hectares mapeados. 96,8\% do total mapeado correspondem à classes que caracterizam um uso conflitante do solo legalmente destinados a preservação. Mesmo sendo uma região caracterizada pela produção de cacau, a paisagem das APP's pertencentes a zona rural do município apresentou predominância de pastagens. A Tabela III traz a porcentagem equivalente a cada classe de uso conflitante das APPs mapeadas:

Tabela III - Dimensão das classes de uso da terra, exceto Mata Atlântica

\begin{tabular}{ccc}
\hline Classes de Uso do Solo & Uso Conflitante & Porcentagem (\%) \\
\hline Mata Atlântica & - & - \\
Pastagens & 132 & 36,4 \\
Zonas Urbanizadas & 180,1 & 49,8 \\
Atividades Industriais & 6,2 & 1,7 \\
Áreas Degradadas & 43,8 & 12,1 \\
\hline Total & 362,1 & 100 \\
\hline
\end{tabular}

A presença de pastagens nessas áreas possibilita o escoamento superficial acelerado e consequentemente atividades erosivas de forma acentuada, considerando que a capacidade de retenção de água desse tipo de fitofisionomia é reduzida quando comparada a presença de vegetação desenvolvida. Além da erosão causada pela ação das chuvas, dos ventos e das atividades fluviais, ao longo do tempo esse tipo de terreno ocasiona a perda de fertilidade e a agregação do solo, implicando na formação de eventuais áreas degradadas (PIRES et al. 2001).

Os atuais problemas urbanos relacionados ao estado ambiental do rio Cachoeira são sentidos de forma efetiva nas áreas urbanas. Nas últimas duas décadas (PINHO, 2001), tornaram-se frequentes e recorrentes eventos de cheias em bairros ribeirinhos, além de perda de patrimônios relacionada a instabilidade do terreno ciliar. No total, são 10,6 km de extensão o trecho do rio Cachoeira na cidade de Itabuna, que além da zona central, perpassa outros quinze bairros. 


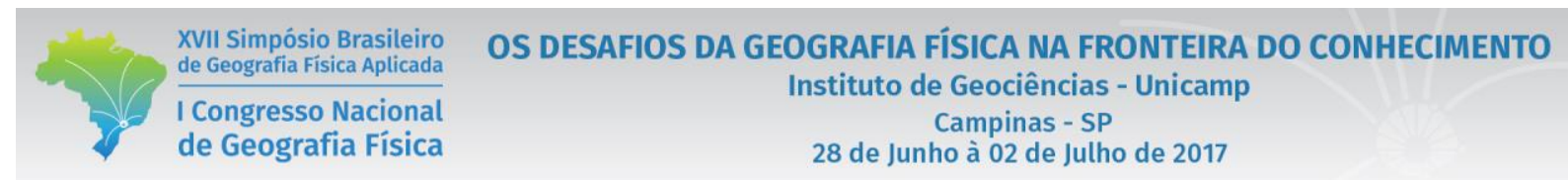

Dessa forma, o uso conflitante do solo nas áreas destinadas ás APP’s são dominados por paisagens urbanas, frisando que, historicamente, áreas de várzea e leitos maiores de canais fluviais são vetores de urbanização devido a topografia aplainada, de fácil retrabalhamento para a obras de engenharia (MASCARENHAS $e t$ al., 2009). A Figura 2 expõe parte do cenário urbano pertencentes ás áreas de APP's:

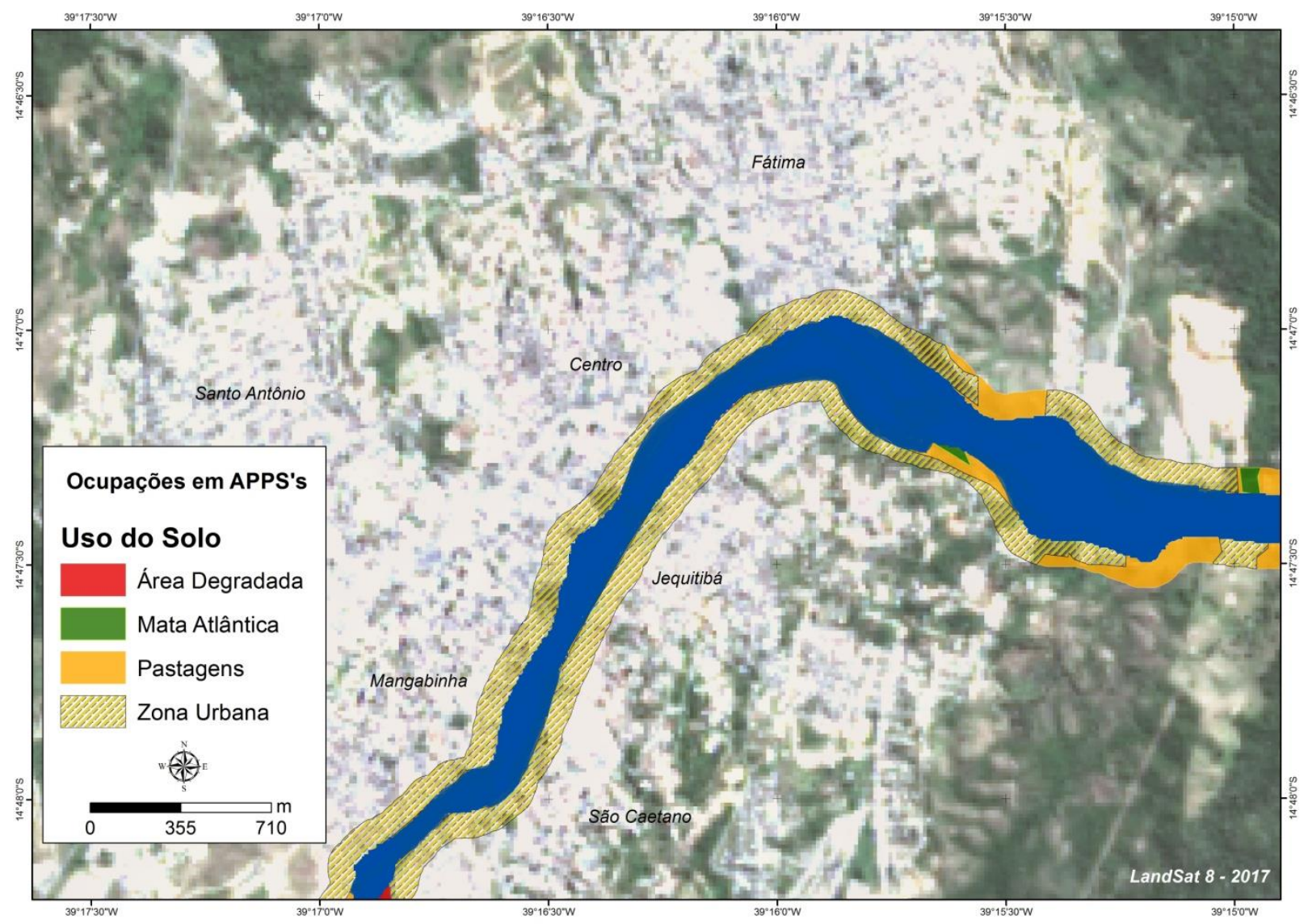

Figura 2 - Destaque para as áreas de APP's na cidade de Itabuna

\section{Conclusões}

No que concerne a aplicação da metodologia do uso de buffer's gerados em ambientes de Sistemas de Informações Geográficas, constata-se a facilidade em que tal ferramenta tem em contribuir com delimitações precisas de áreas de preservação permanente conforme estipula o Código Florestal Brasileiro. Cabe frisar também que a articulação desses buffer's com mapeamentos de uso da terra é imprescindível em estudos que envolvam usos conflitantes.

Em relação as APP's mapeadas ao longo do rio Cachoeira, o total de 96,8\% de classes que correspondem a ausência de cobertura vegetal caracteriza um ambiente hidrográfico degradado em termos de composição 
ciliar, possibilitando ao longo do tempo um assoreamento em nível acentuado do leito do rio. A manutenção dessas áreas apresenta-se como emergencial no sentido de que, parte de problemas ambientais que atingem a cidade de Itabuna, estão associados a eventos ligados a presença do rio Cachoeira, como enchentes e prejuízos materiais a população.

\section{Bibliografia}

ANDRADE, L. M. S. ROMERO, M. A. B. A importância das áreas ambientalmente protegidas nas cidades. in: XI Encontro Nacional de pós-graduação e pesquisa em planejamento urbano e regional - ANPUR. Salvador/BA. 2005.

BRASIL. Resolução do CONAMA 303, de 20 de março de 2002, Dispõe sobre os parâmetros, Definições e limites de Áreas de Preservação Permanente. Brasília, DF: Congresso Nacional, 2002.

LOBÃO, D. E. SETENTA W. C. VALLE, R. R. Sistema Agrossilvicultural Cacaueiro - modelo de agricultura sustentável. Agrossilvicultura (Brasil), v. 1, n. 2, p. 163-173. 2004.

MASCARENHAS, L. M. A. FERREIRA, M. E. FERREIRA, L. G. Sensoriamento Remoto com instrumento de controle e proteção ambiental: análise da cobertura vegetal remanescente na bacia do rio Araguaia. Sociedade $\&$ Natureza, v. 21, n. 1, Uberlândia, 2009.

NOWATZKI, A. SANTOS, L.J.C. PAULA, E. V. Utilização do SIG na delimitação das áreas de preservação permanente (APP's) na bacia do rio sagrado (Morretes/PR). Sociedade \& Natureza, Uberlândia, 22 (1): 107-120. 2010.

PESC. Geoprocessamento aplicado ao planejamento da paisagem do mini-corredor ecológico PESC Boa Esperança. Ilhéus. Relatório de Pesquisa. 2012

PINHO, A. G. Estudo da qualidade das águas do Rio Cachoeira - Região Sul da Bahia. Dissertação de Mestrado em Desenvolvimento Regional e Meio Ambiente. Universidade Estadual de Santa Cruz. Ilhéus - BA. 133p. 2001.

PIRES, J. S. R.; SANTOS. J. E. DEL PRETTE, M. E. A utilização do conceito de bacia hidrográfica para a conservação dos recursos naturais. In: SCHIAVETTI, A. CAMARGO, A. F. Conceitos de bacias hidrográficas: teorias e aplicações. Ilhéus-BA, Editus, 2002.

SILVA, K.B. GOMES R.L., REGO, N.A.C. Social and Environmental hydrographics implications of the land use in the plain and coastal boards between Ilhéus and Olivença - BA. Journal of Hyperspectral Remote Sensing. N ${ }^{\circ} 01$, pag. 03-26. 2015. 